\title{
INTERNATIONAL ISHARES—AN ALTERNATIVE TO INTERNATIONAL PORTFOLIO INVESTMENT
}

\author{
Hsing Fang, California State University Los Angeles
} James Refalo, California State University Los Angeles

dx.doi.org/10.18374/JIFS-13-1.8

\begin{abstract}
International iShares exchange-traded funds (ETFs) provide U.S. investors with the ability to track an entire international capital market by a single transaction. The performance and diversification benefits of international iShares are examined. It is found that U.S. stock market experienced a lower average annual return in the past ten years and since fund inception. U.S., Asian, and European region stock markets are highly correlated, but international iShares have a significantly greater home market beta than a U.S. market beta. This suggests some diversification benefit for international iShares in mitigating U.S. stock market investment risk.
\end{abstract}

Keywords: iShares, ETF, Exchange-traded Funds, Diversification, Portfolio Risk. 